UCRL-ID-132478

\title{
October 1998 Working Group Meeting on Heavy Vehicle Aerodynamic Drag: Presentations and Summary of Comments and Conclusions
}

Rose McCallen, Walt Rutledge

Don McBride, Kambiz Salari

Fred Browand, Anthony Leonard

Jim Ross, Bruce Storms

J.T. Heineck

October 1998

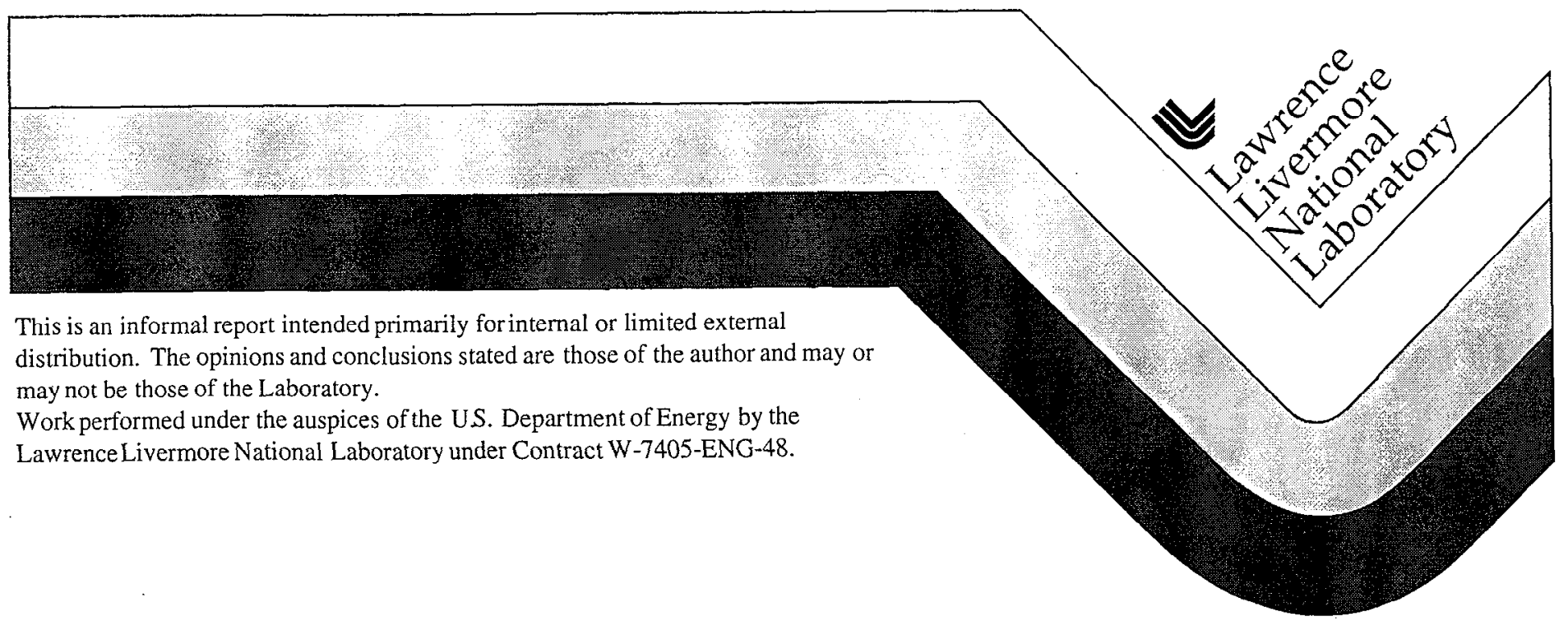




\section{DISCLAIMER}

This document was prepared as an account of work sponsored by an agency of the United States Government. Neither the United States Government nor the University of California nor any of their employees, makes any warranty, express or implied, or assumes any legal liability or responsibility for the accuracy, completeness, or usefulness of any information, apparatus, product, or process disclosed, or represents that its use would not infringe privately owned rights. Reference herein to any specific commercial product, process, or service by trade name, trademark, manufacturer, or otherwise, does not necessarily constitute or imply its endorsement, recommendation, or favoring by the United States Government or the University of California. The views and opinions of authors expressed herein do not necessarily state or reflect those of the United States Government or the University of California, and shall not be used for advertising or product endorsement purposes.

This report has been reproduced directly from the best available copy.

Available to DOE and DOE contractors from the Office of Scientific and Technical Information

P.O. Box 62, Oak Ridge, TN 37831

Prices available from (615) 576-8401, FTS 626-8401

Available to the public from the

National Technical Information Service

U.S. Department of Commerce

5285 Port Royal Rd.,

Springfield, VA 22161 


\title{
October 1998 \\ Working Group Meeting on \\ Heavy Vehicle Aerodynamic Drag:
}

\section{Presentations and Summary of Comments and Conclusions}

\author{
Jointly written by
}

\section{Lawrence Livermore National Laboratory \\ Sandia National Laboratories \\ University of Southern California \\ California Institute of Technology \\ NASA Ames Research Center}

\section{Introduction}

A Working Group Meeting on Heavy Vehicle Aerodynamic Drag was held at NASA Ames Research Center, Moffett Field, California on October 22, 1998. The purpose of the meeting was to present an overview of the computational and experimental approach for modeling the integrated tractor-trailer benchmark geometry called the Sandia Model and to review NASA's test plan for their experiments in the $7 \mathrm{ft} \times 10 \mathrm{ft}$ wind tunnel. The present and projected funding situation was also discussed.

Presentations were given by representatives from the Department of Energy (DOE) Office of Transportation Technology Office of Heavy Vehicle Technology (OHVT), Lawrence Livermore National Laboratory (LLNL), Sandia National Laboratories (SNL), and NASA Ames Research Center.

This report contains the technical presentations (viewgraphs) delivered at the Meeting, briefly summarizes the comments and conclusions, and outlines the future action items. 


\section{Overview of the Project, Current Funding, and Future Workshop}

An overview of the project was presented by Rose McCallen of LLNL. The viewgraphs are enclosed.

Jules Routbort from Argonne National Laboratory attended the meeting as the DOE OHVT representative and presented the funding situation for this effort. Table 1 summarizes the project funding.

TABLE 1. Funding

\begin{tabular}{|l|c|c|}
\hline & FY 98 & FY 99 (\$ distributed to date) \\
\hline LLNL & $\$ 100 \mathrm{~K}$ & $\$ 170 \mathrm{~K}(\$ 100 \mathrm{~K})$ \\
\hline SNL & $\$ 100 \mathrm{~K}$ & $\$ 80 \mathrm{~K}(\$ 30 \mathrm{~K})$ \\
\hline USC & $\$ 50 \mathrm{~K}$ & $\$ 80 \mathrm{~K}(\$ 80 \mathrm{~K})$ \\
\hline Caltech & $\$ 50 \mathrm{~K}$ & $\$ 80 \mathrm{~K}(\$ 80 \mathrm{~K})$ \\
\hline NASA & $\$ 25 \mathrm{~K}$ & $\$ 25 \mathrm{~K}(\$ 0 \mathrm{~K})$ \\
\hline & & \\
\hline Totals & $\$ 325 \mathrm{~K}$ & $\$ 435 \mathrm{~K}(\$ 290 \mathrm{~K})$ \\
\hline
\end{tabular}

NASA requested that their FY 99 allocation be distributed as soon as possible to cover testing costs.

It was noted that the current budget does not provide funds for the Fall 99 Workshop. LLNL policies do not allow commitment to a location and date without the required funds in hand. It was suggested that the Workshop be scheduled in conjunction with the SAE Truck and Bus Conference, Detroit, Michigan in November 1999. Jules Routbort supplied a contact in the DOE/OHVT that is affiliated with SAE that could possibly provide assistance.

\section{Computational Issues Related to the NASA Experiment}

An overview of the Reynolds-averaged Navier Stokes (RANS) modeling being performed by SNL was presented by Kambiz Salari. Current efforts involve the modeling of past experiments on the Sandia Model performed in the Texas A\&M wind tunnel. For these RANS simulations the computational field extends to the wind tunnel walls with slip boundary conditions (no penetration) at the walls. The computational meshes for the RANS simulations range from 10 to 30 million zones.

The large-eddy simulation (LES) approach being used by LLNL was presented by Rose McCallen. Issues related to boundary conditions, subgrid-scale modeling, and data analysis were discussed. It is anticipated that the converged LES solution will require finer mesh discretization than the RANS solution. Proposals to reduce the extent of the computational domain by moving boundaries closer to the model, away from tunnel walls, were criticized with warnings that this can introduce approximately $2.5 \%$ error in the solution. 
Also stressed was the importance of having the time variation of the three velocity components for LES model validation, which will be provided by the NASA experiments in the truck wake.

Further discussions on LES involved wall modeling (i.e., approximations at walls to reduce discretization requirements). Kambiz Salari of SNL has information on a method he called ODT. He will provide the reference to the team.

\section{NASA Wind Tunnel Test Plan}

Bruce Storms presented NASA's test plan for the experiments on the Sandia Model in the $7 \mathrm{ft} \times 10 \mathrm{ft}$ wind tunnel scheduled for January 1999, and J.T. Heineck presented information on the particle image velocimetry (PIV) measurements planned for the test. Their presentations are enclosed. There were informal discussions with NASA's Dave Driver on his oil film interferometry technique (OFI) for measuring skin friction and with NASA's James Bell on his pressure sensitive paint (PSP) measurements. These techniques will also be used in the wind tunnel tests. Afternoon activities included wind tunnel tours.

The viewgraphs from the formal presentations provide details on the wind tunnel dimensions, measurement accuracies, and the test plan. The specific issues raised during the presentations and informal discussions are reviewed below.

The wind tunnel test section is $15 \mathrm{ft}$ long, $10 \mathrm{ft}$ wide, and $7 \mathrm{ft} \mathrm{high}$. There is a $1 \%$ divergence on the side walls only. The front end of the vehicle will be placed approximately 6 inches from the wind tunnel contraction section where the two-dimensional time-averaged inlet velocity profile will be provided. It was suggested that by using a potential flow calculation, this inlet profile could be projected farther upstream for use as the inlet condition to the computational models. In this way the blockage effects by the vehicle will be more accurately captured. The boundary layer thickness at the beginning of the $7 \mathrm{ft} x 10 \mathrm{ft}$ test section is 2.1 inches and the displacement thickness is 0.6 inch. The streamwise growth of a turbulent boundary layer can be estimated as $1 \%$ of the run.

The model is mounted on four 1 inch cylindrical posts so that the base of the truck is 3 inches from the tunnel floor. Fairings will be placed around the posts to seal the floor openings, as was done in the Texas A\&M tests. The fairings are also cylindrical with approximately a 1/8 inch gap between the posts and fairings. The fairings contribute are expected to significantly disturb the body underflow and thus, should be included in the calculations.

The proposed test conditions are $200 \mathrm{mph}$ wind velocities for a Reynolds number (Re) of 2 million and a Mach number (Ma) of 0.27 . This wind velocity corresponds to a full size truck traveling at approximately $24 \mathrm{mph}$. Concerns were raised as to the high Mach number flow (i.e., compressibility effects are usually negligible below Ma of 0.1 ). The necessity for the high flow velocities stems from the need to improve the accuracy of the PSP and increase the loads for the facility balance measurements. Higher vclocitics result in higher pressures which improves the accuracy of these measurements. The PIV accuracy is not dependent on the velocity magnitude in the range of interest. Since the ultimate goal 
is to obtain data for validation of our computational incompressible flow models, it was suggested that if a range of Re can be considered, possibly one case at or below Ma of 0.1 be included (i.e., approximately $74 \mathrm{mph}$ winds in tunnel, $\mathrm{Re}=740,000$, and real truck speed of approximately $10 \mathrm{mph}$ ).

It is expected that 2 yaw angles (e.g., 5 and 10 degrees off of center) will be attempted for PSP and OFI measurements and 1 yaw angle for the PIV measurement. The reduction of yaw angles for the PIV measurements is due to the excessive setup time for each yaw angle change compared to the setup time for the other measurement techniques. For validation of the computations, we would prefer to have the more significant change in flow characteristics caused by a 10 degree yaw. However, if more data can be acquired for the reduced angle of 5 degrees, this smaller angle may be a better choice. The NASA team will take a closer look at these issues and provide more information to make the optimum choice. The drag at 0 degrees and each yaw angle will be measured and the wind averaged drag (i.e., drag averaged over yaw angles) will be calculated from this limited sample.

The PIV measurements will be taken in the model wake, providing the three components of velocity in the plane of a laser sheet. Two options were presented for the orientation of the laser sheet. The first choice is to position the laser sheet normal to the stream and choose slices over a 13.5 inch distance behind the model in the streamwise direction. The second choice is to position the laser sheet in the streamwise direction and sweep along the direction normal to the flow, keeping one side of the sheet as close as possible to the backend of the model. With the first choice, it will be difficult to determine streamwise effects because the results in the streamwise direction are measured at different setups and matching the phase of the solution will be difficult. However, streamwise normal vortical roll ups will be observed directly. The second choice will more clearly provide the time evolution of vortices, but the difficulty will be to patch together the picture of the flow in the cross stream direction. The ideal solution may be to provide results from both setup options but settle for less data in each configuration. NASA's J.T. Heinech will further investigate the possibility of acquiring results at both orientations by limiting the yaw angle and piggy backing on experiments directly following our test that require an alternate laser sheet orientation.

The PSP measurements will provide time averaged pressures. There was some discussion on obtaining time-dependent pressures with PSP, since the camera has a $20 \mathrm{~Hz}$ sampling rate (at \pm 7 psf accuracy). However, setting up for time-dependent measurements by January would be a stretch.

The OFI technique can supply quantitative time-averaged skin friction measurements. The technique requires a shinny surface, which is obtained by applying mylar to the model surface. It was suggested that for this test the OFI measurements be used to determine the separation and reattachment positions on the floor of the tunnel in the wake of the model, since hot-film measurements of skin friction are already going to be measured on the model body. Skin friction measurements on the model body will be provided by Taos hotfilm system which can detect flow separation, reattachment, and transition. In the 0 degree (no yaw) case, it is expected that the boundary layer on the top and side walls of the model will transition around the midsection of the model. The approximate locations of separa- 
tion and reattachment positions for each of the 2 yaw angles are needed to determine the best positions for the hot-film system. This information is not available from the past Texas A\&M tests nor from previous SNL R $\Lambda$ NS computations.

To summarize, many of the questions raised were either resolved at the meeting or some guidance was provided to the NASA experimental team so that decisions can be made on optimum instrument positioning or desired flow conditions. However, the question that still requires a timely answer from the computational team is what are the optimum positions for the hot-film system for skin friction measurements of separation, reattachment, and transition. A one month lead time is needed for any moderate experiment changes from the current test plans.

\section{Future Meetings}

The next meeting will take place via conference call and will again focus on the NASA 7 $\mathrm{ft} \times 10 \mathrm{ft}$ wind tunnel tests. This meeting should be held before December 1, 1998 to provide 1 month lead time for modifications in the tests scheduled for January 1999. It is expected that several of the Truck Aero Team members will be interested in visits to NASA to observe the actual testing in January 1999.

\section{Action Items}

The follow-on prioritized action items with the individuals responsible for the tasks are as follows:

1. Provide guidance for positioning hot-film system for skin friction measurements. Kambiz Salari of SNL will investigate the possibility of running a 5 or 10 degree yaw case with the RANS model. (R. McCallen and K. Salari)

2. Provide NASA with the size of the fairings to be placed on the supporting cylindrical posts. (K. Salari)

3. Reevaluate times for laser sheet and camera positioning for various yaw positions and laser sheet orientations to assist in developing a prioritized list of measurements for PIV. (J.T. Heineck and B. Storms)

4. Provide references on NASA's PIV techniques to be used in our experiments. (J.T. Heineck)

5. Detailed description of $7 \mathrm{ft} \times 10 \mathrm{ft}$ wind tunnel. (B. Storms)

6. Provide reference on wall modeling method for LES. (K. Salari)

7. Call SAE contact in DOE/OHVT for assistance with scheduling of Fall 99 Workshop with the SAE Truck and Bus Conference. (R. McCallen)

8. Setup conference call and agenda for next meeting. (R. McCallen) 
Truck Aero Team Meeting

NASA Ames, CA

October 22, 1998

$\underline{\text { Attendee List }}$

$\begin{array}{lll}\text { Attendee } & \text { Organization } & \text { e-mail address } \\ \text { James Bell } & \text { NASA Ames } & \text { jhbell@mail.arc.nasa.gov } \\ \text { Dave Driver } & \text { NASA Ames } & \text { ddriver@mail.arc.nasa.gov } \\ \text { J.T. Heineck } & \text { NASA Ames } & \text { jheineck@mail.arc.nasa.gov } \\ \text { Barbara Kornblum } & \text { LLNL } & \text { kornblum1@llnl.gov } \\ \text { Donald McBride } & \text { SNL } & \text { ddmcbri@sandia.gov } \\ \text { Rose McCallen } & \text { LLNL } & \text { mccallen1@llnl.gov } \\ \text { Jim Ross } & \text { NASA Ames } & \text { jcross@mail.arc.nasa.gov } \\ \text { Jules Routbort } & \text { ANL/DOE } & \text { routbort@anl.gov } \\ \text { Kambiz Salari } & \text { SNL } & \text { ksalari@sandia.gov } \\ \text { Bruce Storms } & \text { NASA Ames } & \text { bstorms@mail.arc.nasa.gov }\end{array}$


- Agenda -

\section{Truck Aero Team Meeting \\ NASA Ames, CA}

\section{October 22, 1998}

\section{Purpose of Meeting}

Present computational and experimental approach

Review experimental test plan

Discussions and sharing of ideas

\section{Introduction}

Project Overview (Rose McCallen, LLNL)

Budget (Jules Routbort, DOE/ANL)

\section{Computational Work}

RANS Modeling (Kambiz Salari, SNL)

LES Modeling (Rose McCallen, LLNL)

\section{Experimental Work and Test Plan}

Test Plan and Instrumentation (Bruce Storms, NASA)

Particle Image Velocimetry Measurements (J.T. Heineck, NASA)

Wind Tunnel Tour

\section{Wrap-up Discussion}

Next Progress Meeting

Near Term Action Items 



\title{
Aerodynamic Design of Heavy Vehicles
}

\section{Overview of Project}

\author{
Rose McCallen, Ph.D.
}

Lawrence Livermore National Laboratory, Livermore, CA

\author{
October 1998
}




\section{The MYPP is based on industry needs and consideration of current technology, funding, and DOE interests.}

DOE and National Laboratory interest

Reduce heavy vehicle drag $\rightarrow$ reduce fuel consumption and emissions

R\&D for DOE programs

Industry needs

Advanced computational tools and experimental methods

- Understand the effects of design changes

- Simulate fully-integrated tractor-trailers

Design improvements for drag reduction

Current technology - CFD is hard!

Reynolds-averaged Navier Stokes (RANS) is common approach

Large-eddy simulation (LES) is in development

DPIV measurements can provide full velocity field measurements

Funding is minimal and we need a plan with a 'near-term impact'

FY99: $\$ 540 \mathrm{~K}(=85 \%$ of requested $\$ 635 \mathrm{~K})$ 


\section{The MYPP focuses on development and demonstration of a simulation capability.}

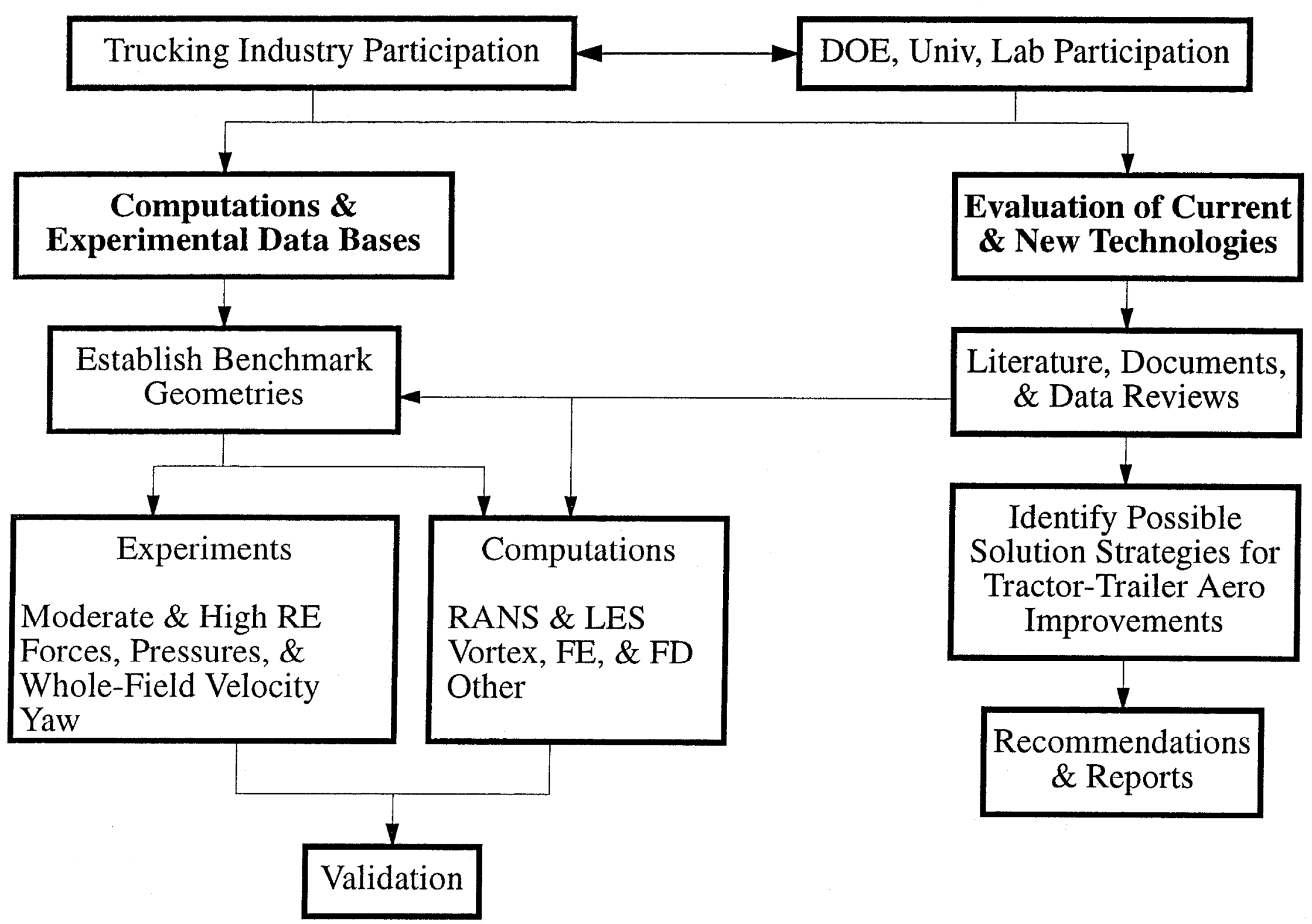


Near-Term Impact: Comparison of RANS and LES and detailed experimental verification for a real truck problem.

Sandia's Model
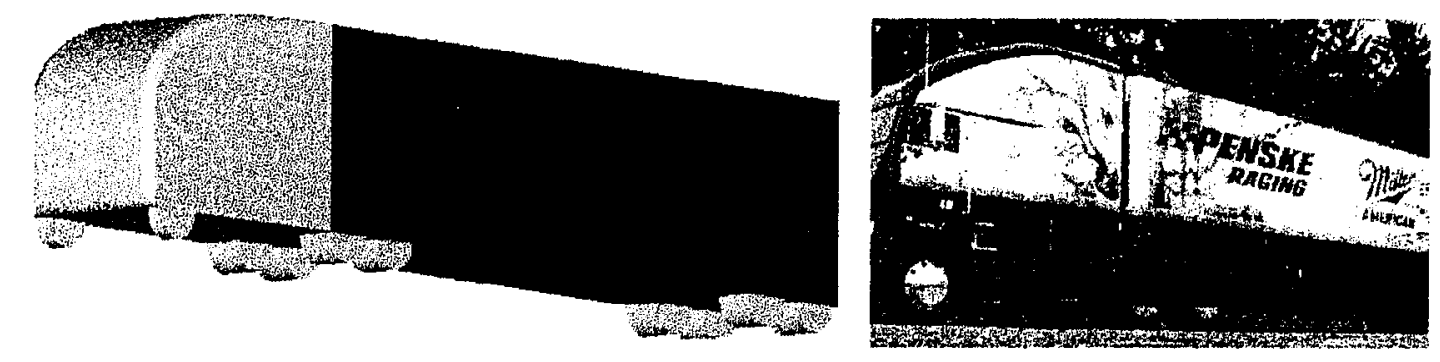

Advantages

Simple geometry with some existing data and some modeling already done The final detail results will be available for comparison to commercial tools

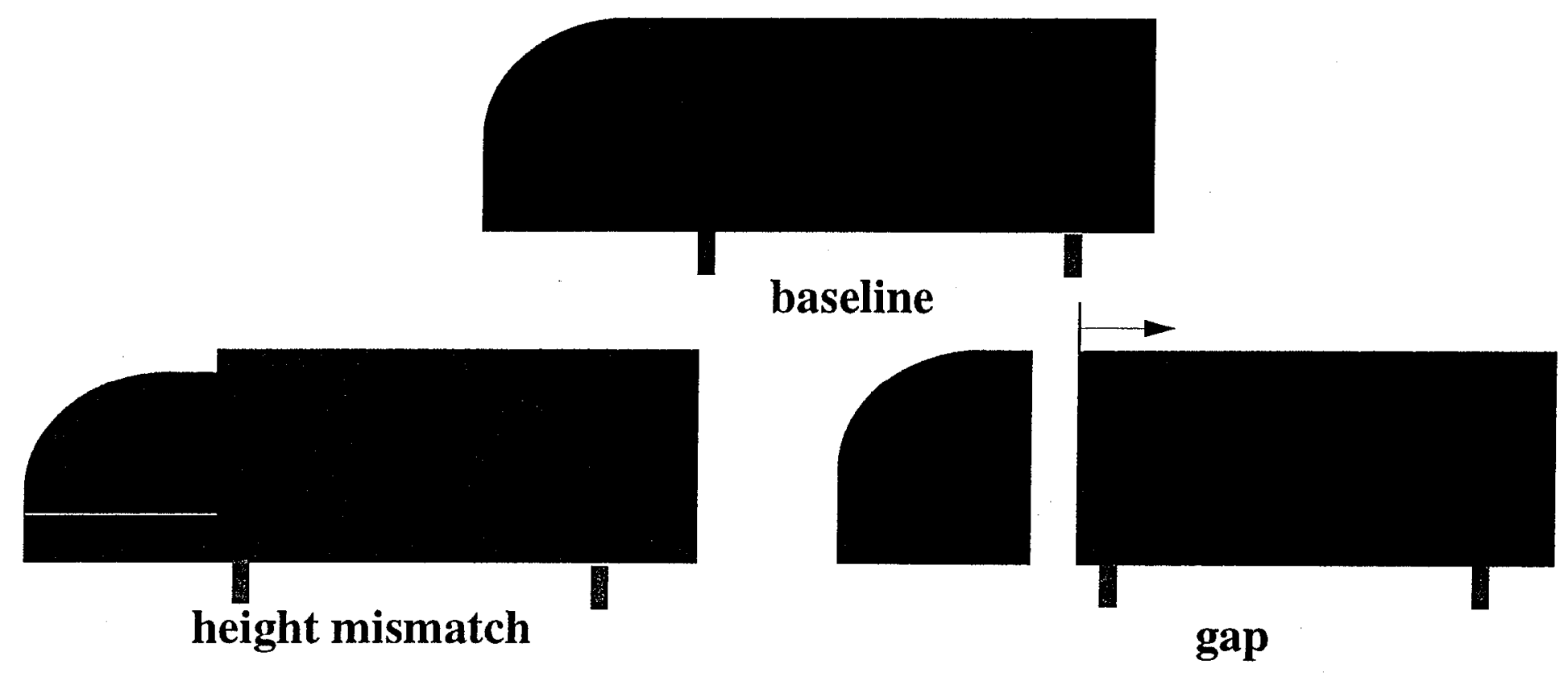




\section{Each organization's contributions are critical to the project's success.}

Computational Modeling

Rose McCallen (PI)

University of California

IID Lawrence Livermore

Large-Eddy Simulation using

Finite Element Methods

Anthony Leonard

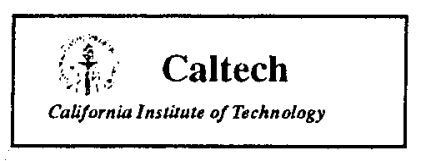

Large-Eddy Simulation using Vortex Methods

Don McBride

Walt Rutledge

Reynolds-Averaged Modeling

using

Finite Difference Methods
Experimental Modeling

Don McBride

Walt Rutledge

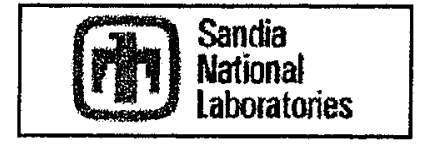

GTS Experiments at Texas A\&M
Fred Browand

\begin{tabular}{|rc|}
\hline USC & UNIVERSITY \\
OF SOUTHERN \\
CALITORNIA
\end{tabular}

Moderate Speed Experiments in Wind Tunnel

\section{Jim Ross}

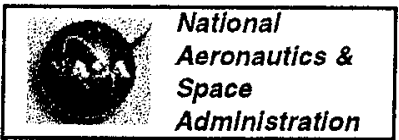

High Speed Experiments in 7'x10' and 12'

Wind Tunnels 


\section{Our near-term tasks have been identified and prioritized.}

Benchmarks

1. Sandia Body

Experiments

- Texas A\&M, Re = 1,600,000

- NASA 7'x10', $\operatorname{Re}=1,600,000$ and other moderate to lowest $\operatorname{Re}$ Oil film interferometry, particle image velocimetry, doppler global velocimetry Upstream mean velocity profile provided 0,5 , and 10 degree yaw conditions

- USC wind tunnel, two Re conditions within $200,000<\operatorname{Re}<400,000$ With and without trailer/tractor height mismatch and gap Computations

- RANS for high and low Re (SNL)

- LES for low Re with some attempt at high Re (LLNL and Caltech)

2. New Model Design (USC)

3. Gene's Model for Re sensitivity study (i.e., how high is enough and drag delta's for components)

- NASA 12', $\operatorname{Re}_{\max }=5,000,000$, model with and without components 


\section{Our budget is not consistent with projected funding.}

\section{FY99 budget : $\$ 540 \mathrm{~K}$}

\begin{tabular}{|l|c|c|l|c|}
\hline & $\begin{array}{c}\text { Computations } \\
\text { \& Experiments }\end{array}$ & $\begin{array}{c}\text { Evaluation of } \\
\text { Current \& New } \\
\text { Technologies }\end{array}$ & Final Report & Total/Year \\
\hline FY98 & $\$ 276 \mathrm{~K}$ & $\$ 34 \mathrm{~K}$ & & $\$ 310 \mathrm{~K}$ \\
\hline FY99 & $\$ 630 \mathrm{~K}$ & $\$ 5 \mathrm{~K}$ & & $\$ 635 \mathrm{~K}$ \\
\hline FY00 & $\$ 1,045 \mathrm{~K}$ & $\$ 188 \mathrm{~K}$ & & $\$ 1,233 \mathrm{~K}$ \\
\hline FY01 & $\$ 1,095 \mathrm{~K}$ & $\$ 188 \mathrm{~K}$ & & $\$ 1,283 \mathrm{~K}$ \\
\hline FY02 & $\$ 855 \mathrm{~K}$ & $\$ 161 \mathrm{~K}$ & & $\$ 1016 \mathrm{~K}$ \\
\hline FY03 & $\$ 818 \mathrm{~K}$ & $\$ 161 \mathrm{~K}$ & & $\$ 979 \mathrm{~K}$ \\
\hline FY04 & $\$ 120 \mathrm{~K}$ & $\$ 124 \mathrm{~K}$ & $\$ 34 \mathrm{~K}$ & $\$ 278 \mathrm{~K}$ \\
\hline TOTAL & & & & $\underline{\$ 5,734 \mathrm{~K}}$ \\
\hline
\end{tabular}


It was necessary to leverage other funding sources.

SNL

- past data obtained at Texas A\&M

Free

- loan of model to NASA

Free

- LES R\&D

LDRD

- computational resources

ASCI

USC

- instrumentation

Caltrans, NSF

Caltech

- LES model development

ASCI, DOD

- computational resources

ASCI, NSF, DOD

NASA Ames

- 7'x10' wind tunnel tests

Free

- 12' wind tunnel tests

1/3 Cost

- Ioan of Navistar's model

Free

LLNL

- computational resources

ASCI

- LES and code development 


\section{The projected milestones are segregated into benchmark cases with advancing levels of complexity.}

Projected milestones for first four years of project (FY98 through FY01)

\begin{tabular}{|l|c|}
\hline \multicolumn{1}{|c|}{ Task } & Milestone \\
\hline Workshop II & $2 / 98$ \\
\hline MYPP with projected budget and milestones & $5 / 98$ \\
\hline Continued site visits & $12 / 98,12 / 99,12 / 00$ \\
\hline $\begin{array}{l}\text { Level 1 Benchmarks: Establish generic shapes and outline } \\
\text { test cases for investigation of trailer-tractor height and gap } \\
\text { mismatch (Demo) }\end{array}$ & $9 / 98$ \\
\hline Test data at moderate Re for Level 1 benchmarks (Demo) & \\
\hline $\begin{array}{l}\text { RANS, LES/FEM, LES/Vortex computations of Level 1 } \\
\text { benchmarks at moderate Re (DEMO) }\end{array}$ & $9 / 99$ \\
\hline Test data at high Re for Level 1 benchmarks (Demo) & $12 / 99$ \\
\hline $\begin{array}{l}\text { RANS, LES/FEM, LES/Vortex computations of Level 1 } \\
\text { benchmarks at high Re (DEMO) }\end{array}$ & $6 / 00$ \\
\hline Workshop III: Possible computation contest & $12 / 00$ \\
\hline Level 2 Benchmarks: Establish generic shapes & $11 / 99$ \\
\hline Test data at moderate and high Re for Level 2 benchmarks & $9 / 99$ \\
\hline
\end{tabular}


. 


\title{
RANS Modeling
}

Kambiz Salari

\author{
Sandia National Laboratories
}




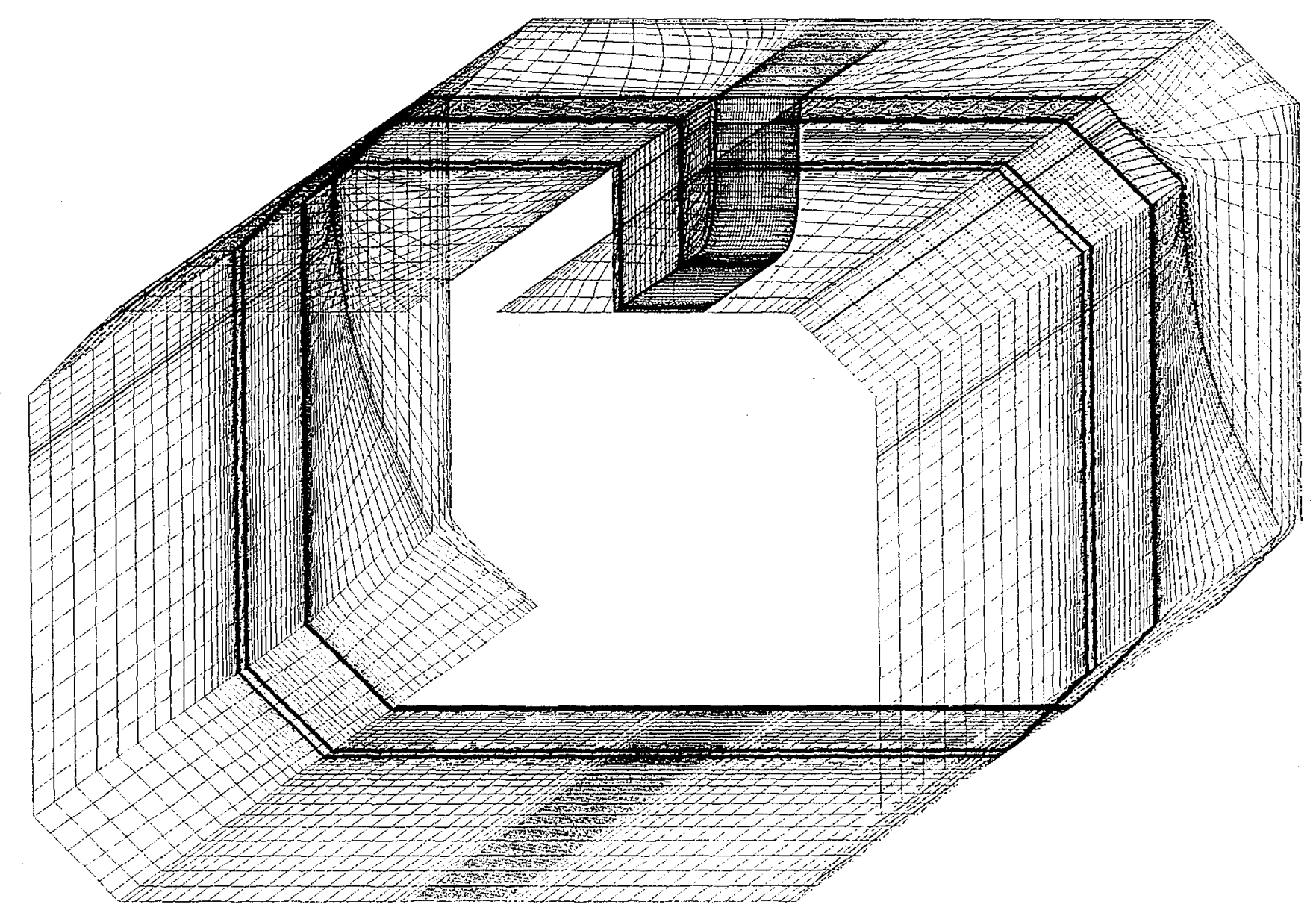




\section{GTS Flow Simulation}

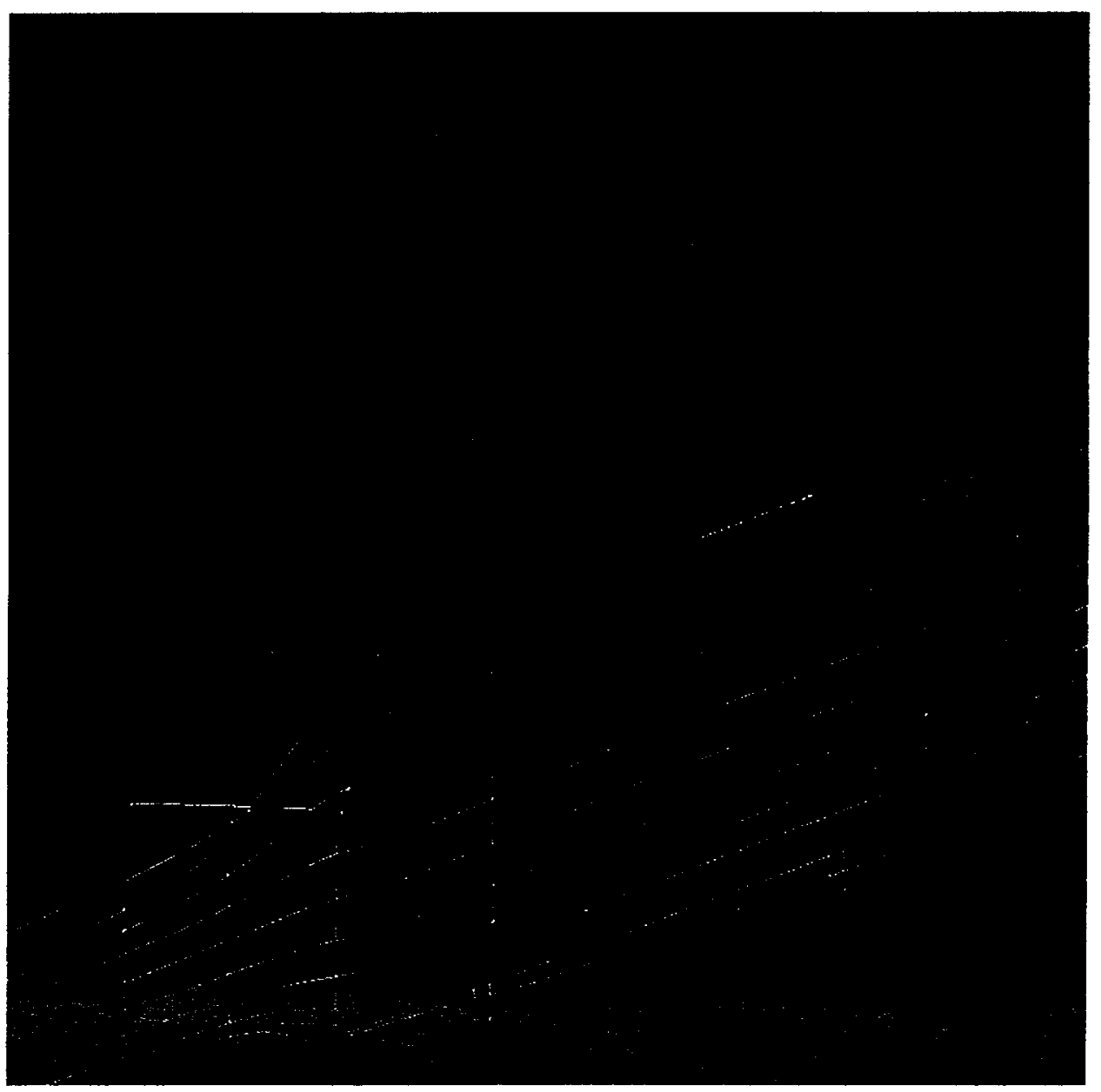

Particle traces, $\operatorname{Re}=1.6 \times 10^{6}$ 


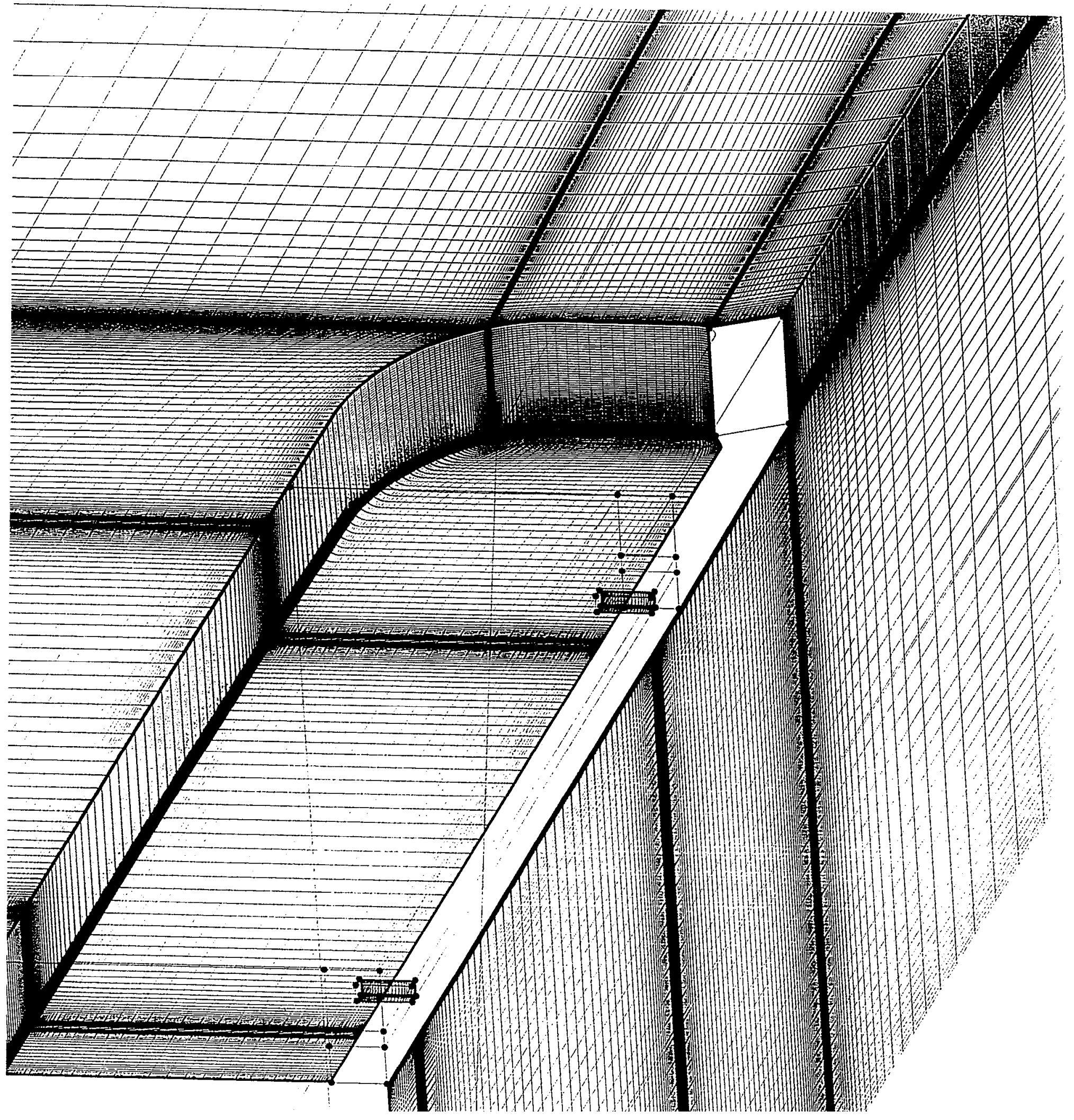


Ground Transportation System (GTS) vehicle

Texas A\&M 7'x10' low speed tunnel test

Test condition:

Run $=31, \operatorname{Re}=1.6 \times 10^{6}$, Wheels removed

Yaw angle $=0$ (deg.)

Free stream velocity $=78(\mathrm{~m} / \mathrm{s})$

Density $=1.17\left(\mathrm{~kg} / \mathrm{m}^{3}\right)$

Static pressure $=99,470.6(\mathrm{~Pa})$

Kinematic viscosity $=1.555 \times 10^{-5}\left(\mathrm{~m}^{2} / \mathrm{s}\right)$ 


\section{Engineering Sciences, Aerosciences Department}

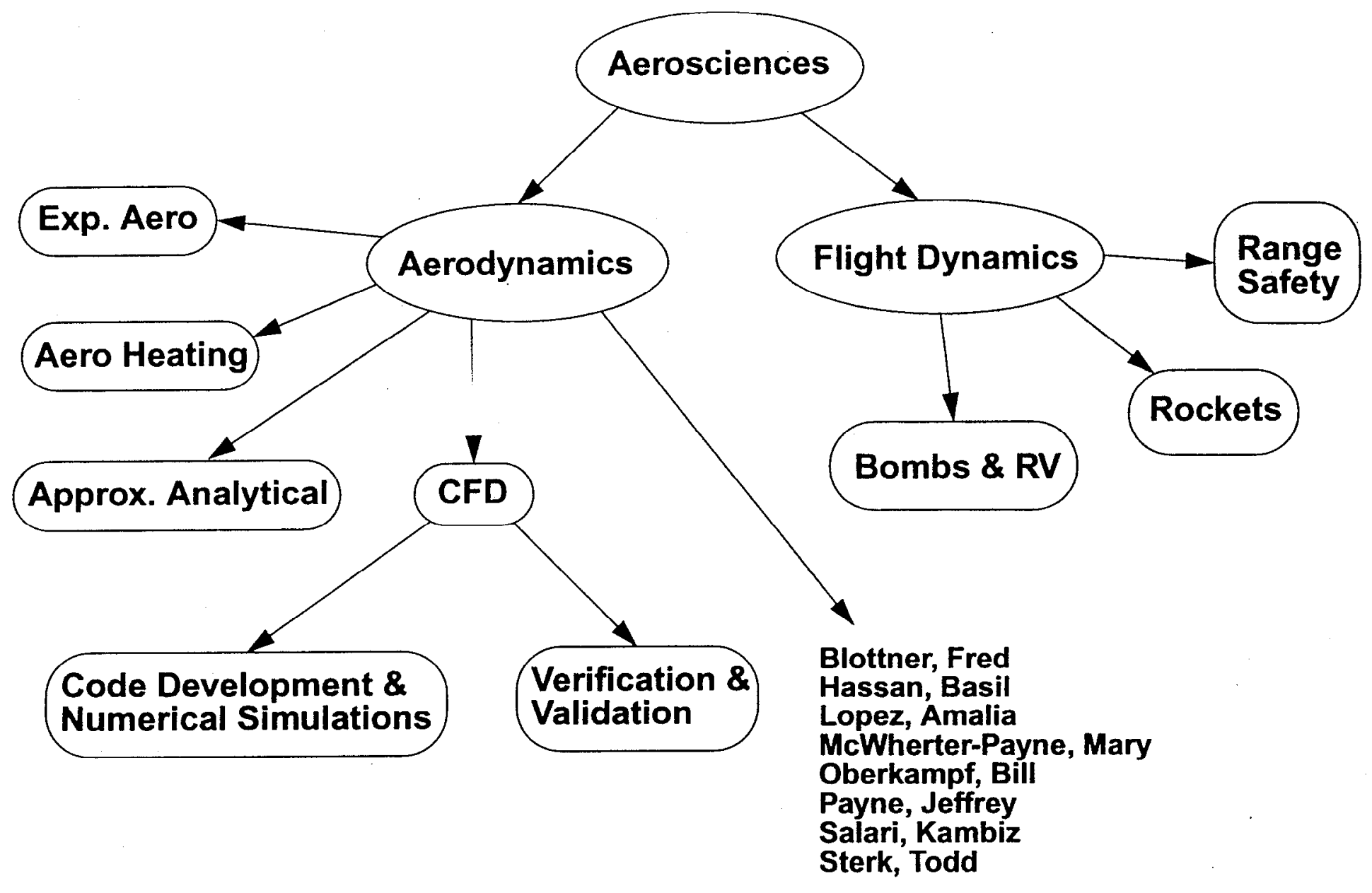




\section{Aero Applications}

- History

- Primarily high speed flow simulations

- Recently, there is an effort in low speed flow simulations

- Advanced Computational Capabilities

- SACCARA (Sandia Advanced Code for Compressible Aerothermodynamics Research and Analysis)

- CFD-ACE (Navier-Stokes code)

- CHAD (Navier-Stokes code)

- NS3D (Navier-Stokes code)

- SPRINT (PNS code)

- SANDIAC (Euler code)

- MGAERO (Euler code)

- HIBLARG (Boundary layer code) 


\section{Code Development \& Numerical Simulation}

- Physics Enhancement through Internal Research Programs

- ESRF/LDRD

- ESRF/Tech Base

- Range of Modeling and Simulation

- Full Navier-Stokes code

- Large Scale Computing (ASCI)

- PNS codes

- Euler Codes

- Boundary Layer codes 


\section{SACCARA Current Capabilities:}

- Based on parallel version of INCA ${ }^{\mathrm{TM}}$ Full Navier-Stokes code

- Implicit, Multi-block, structured grids for 2-D, Axisymmetric, and 3-D flows

- Finite volume discretization (steady and unsteady flows)

- Subsonic --> Hypersonic flow fields

- Ideal, equilibrium, and thermo-chemical nonequilibrium finiterate gas chemistry

- Zero-,one-, and two-equation turbulence

- MP implementation on a variety of distributed parallel architectures (IBM, Intel, etc.) 


\section{Improving Physical Models in SACCARA 团}

Engineering Sciences Center

- Methods to model transition

- Engineering models based on boundary layer

- Parabolized Stability Equations (PSE) approach

- Turbulence models

- One-equation Spalart Allmaras model

- New two-equation $k$ - $\omega$ model

- New two-equation $k-\zeta$ model 


\section{DOE Truck Aero Project}

- History

- SNL GTS Work (RAMPANT), LDRD

- Ahmed-body flow simulation (CHAD), USCAR/SCAAP

- Currently working on

- Gridding the SNL GTS model

- Running flow simulations for the GTS model with SACCARA 

Truck Aerodynamics:

\title{
Large-Eddy Simulation (LES) using the Finite-Element Method (FEM)
}

\author{
Rose McCallen, Ph.D. \\ Lawrence Livermore National Laboratory
}

October 1998 


\section{Large-eddy simulation provides a wealth of information and less empiricism.}

Reynolds-Averaged Navier-Stokes (RANS)

Many empirical parameters

2D, steady, time-averaged solution

Backward-facing step: streamwise velocity

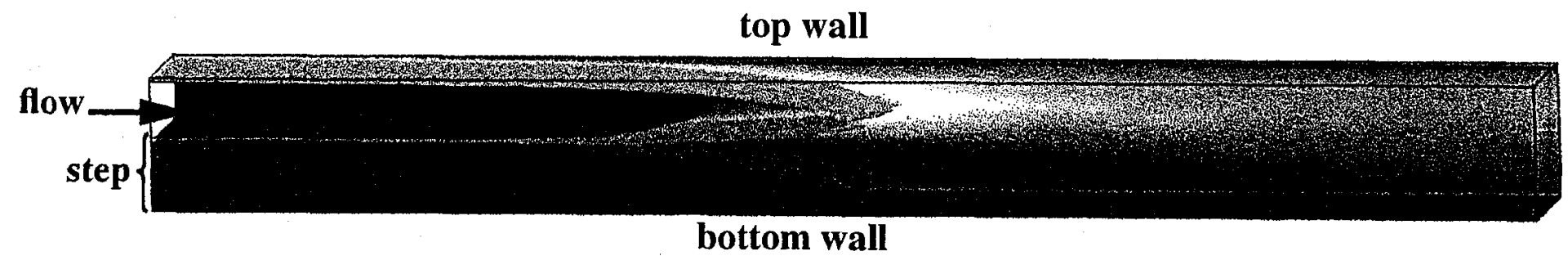

Large-eddy simulation (LES)

One empirical parameter

3D, unsteady solution of vortex shedding

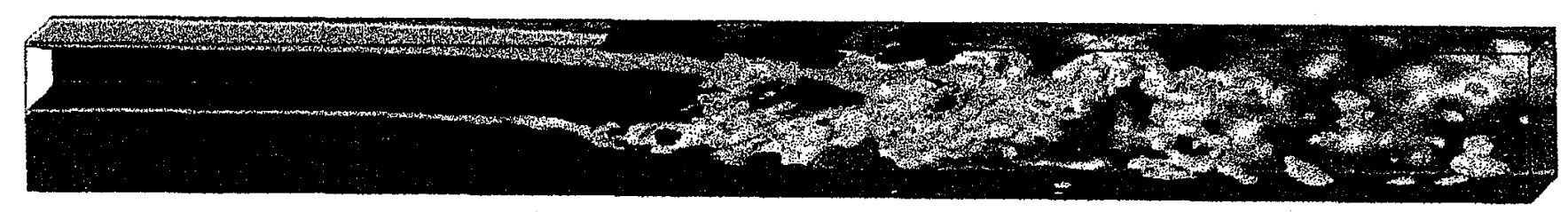


What do advanced tools provide and what are the challenges in developing and using these tools?

Background

LES/FEM

R\&D issues

Data analysis

Time-averaging, visualization, time histories, and power spectrum

Approach 


\section{Turbulent flow contains eddies ranging from large-scale to small-scale.}

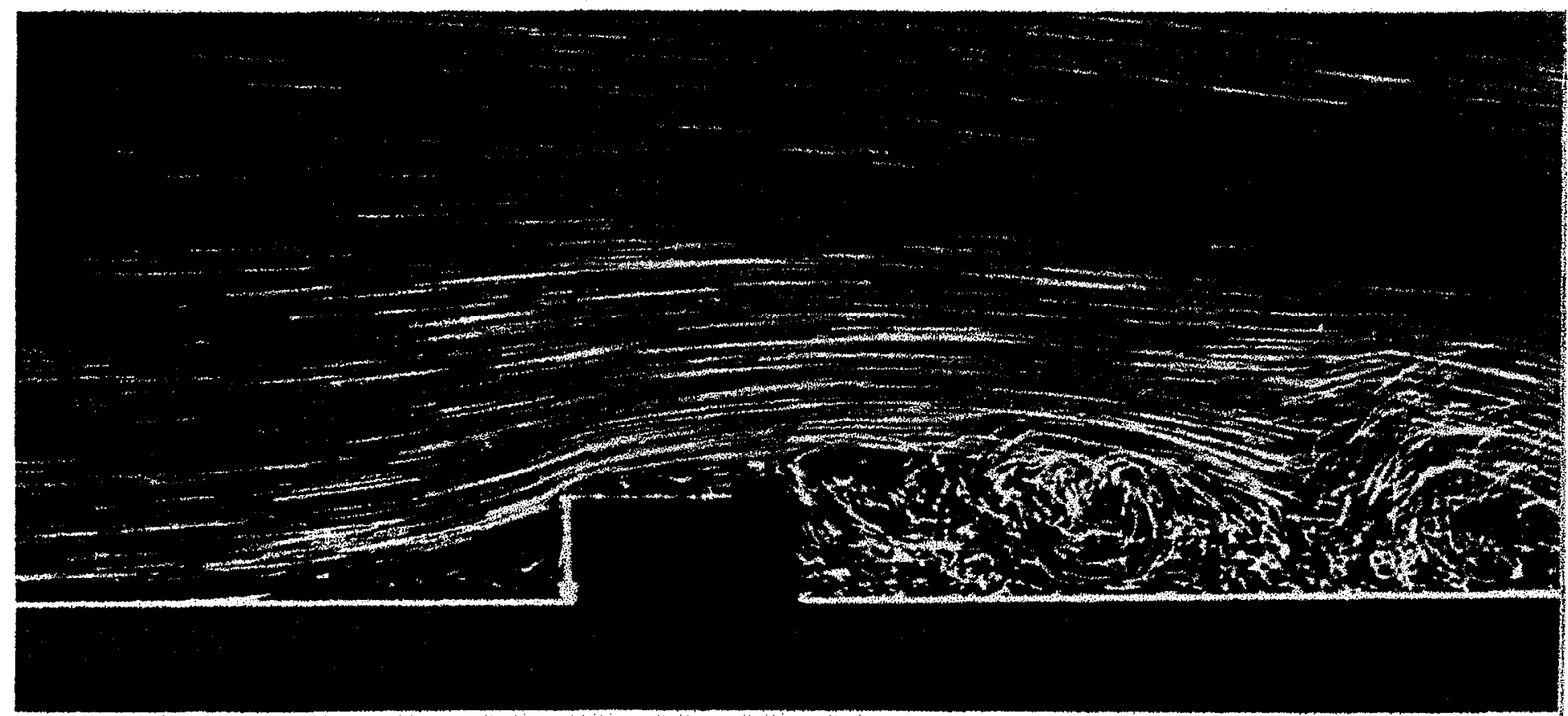

Ref. VanDyke, An Album of Fluid Motion Large-eddy simulation captures the large-scale motion and approximates the small-scale motion.

$$
\begin{aligned}
\text { all turbulent motions } & =\text { large-scale motions }+ \text { small-scale motions } \\
& =\text { 'resolved' scale }+ \text { 'subgrid' scale } \\
u_{\alpha} & =\bar{u}_{\alpha}+u_{\alpha}^{\prime}
\end{aligned}
$$




\section{LES/FEM provides a unique approach for solving practical problems.}

Advantages of LES

Captures 3D time-dependent motion

Less empiricism than other methods

Advantages of FEM

Unstructured meshes

Natural boundary conditions

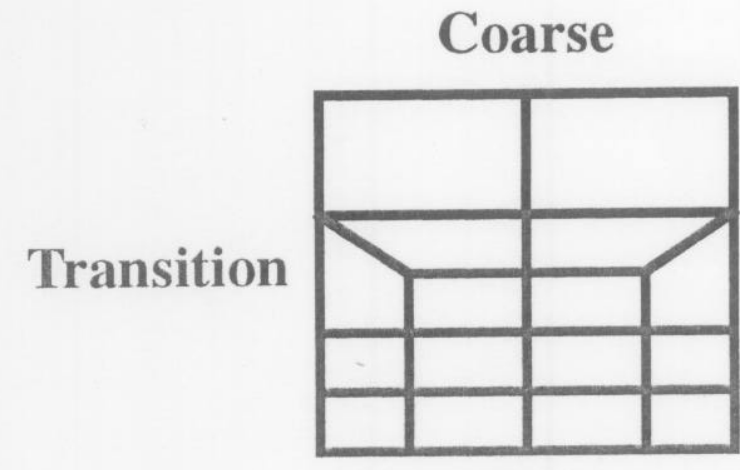

Fine

Coupling to other FEM codes

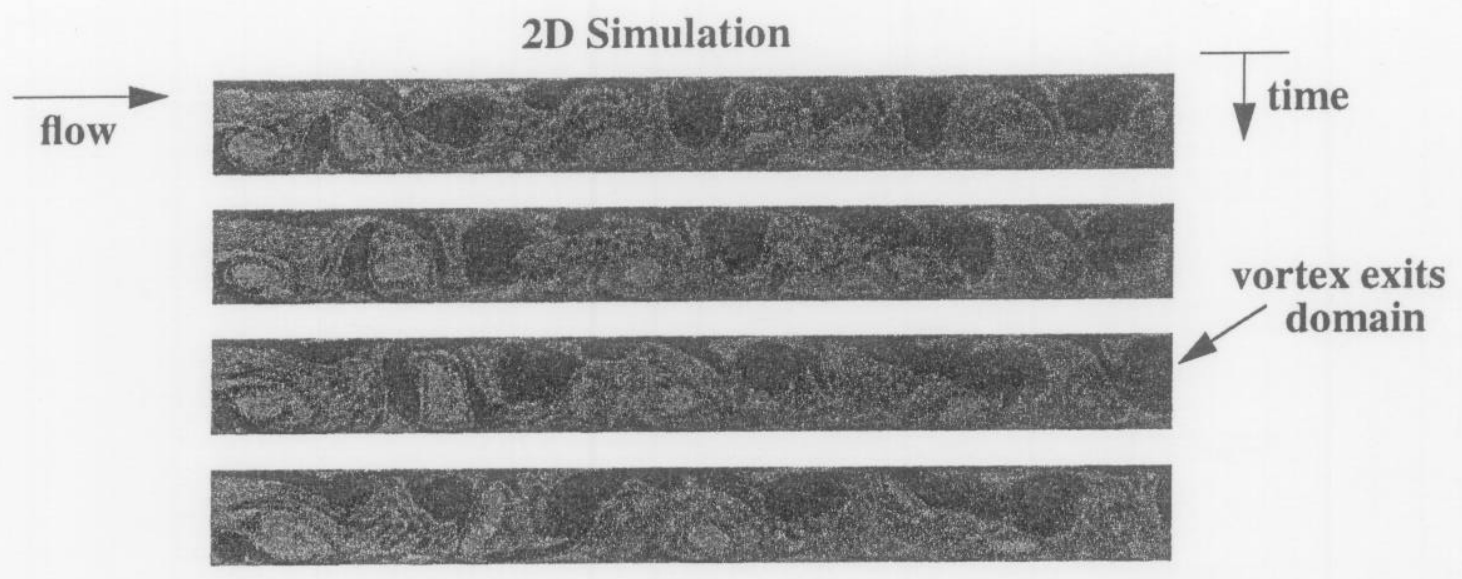

Zero natural boundary conditions capture the vortical outflow 


\section{The challenges are related to physical as well as computational modeling.}
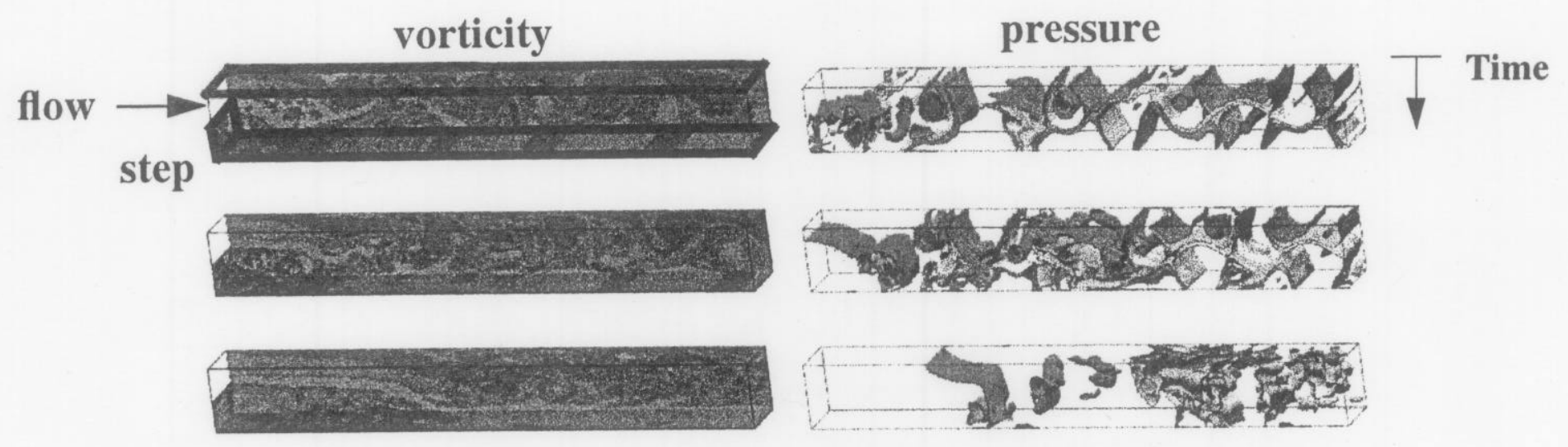

Boundary Conditions No slip/slip, outflow/inflow, periodic

Size and Runtime Resolution of small eddy motion, evolution over long time scales

Mesh Refinement Adaptive, unstructured

Turbulence Models Approximations to reduce problem size and runtimes

Analysis Large data sets, visualization, convergence testing

Numerics Appropriate scheme, parallelization, solvers 


\section{Time histories provide local flow information}
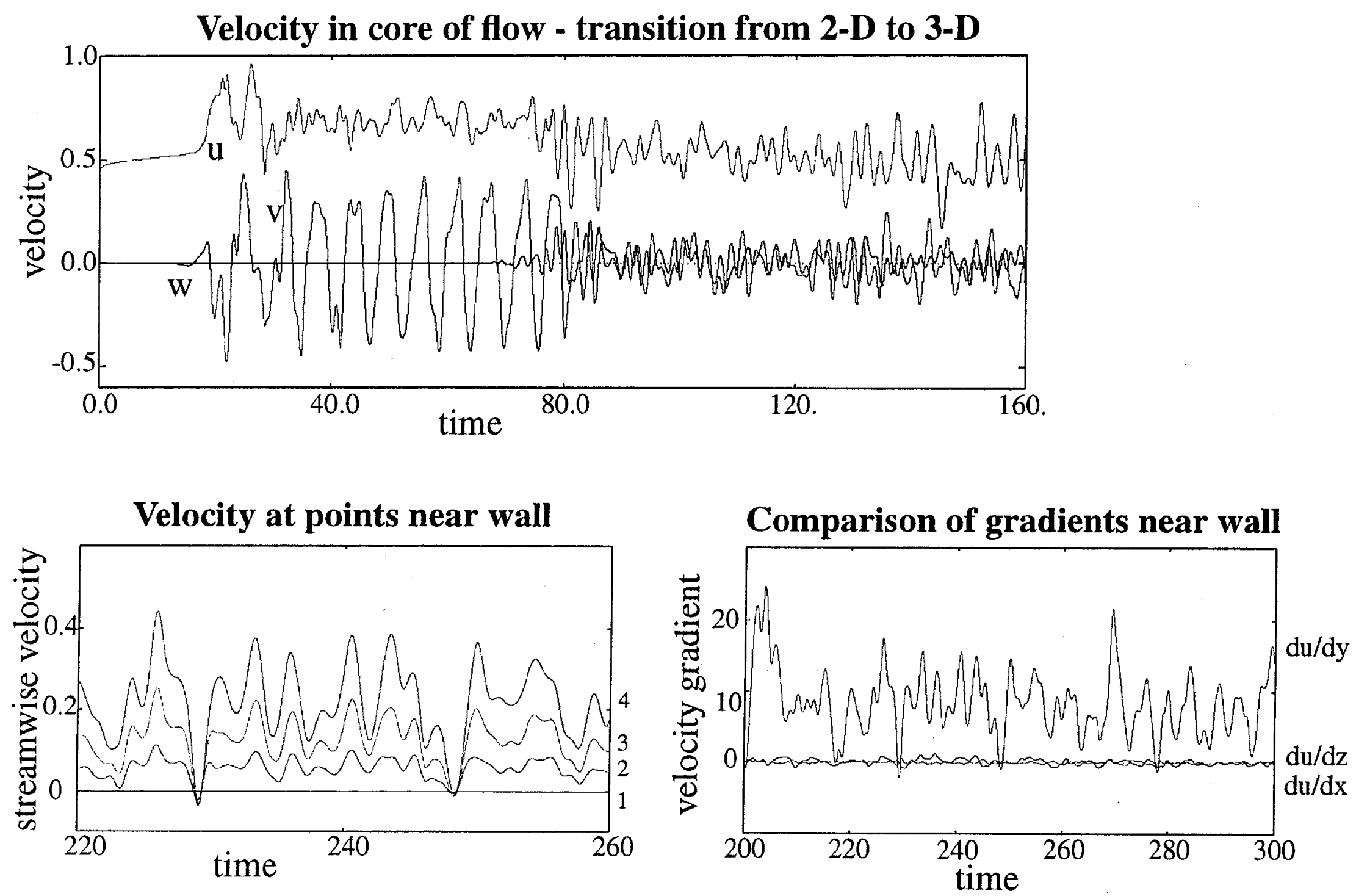


\section{Power spectrum analysis can be used to determine the dominant frequencies.}

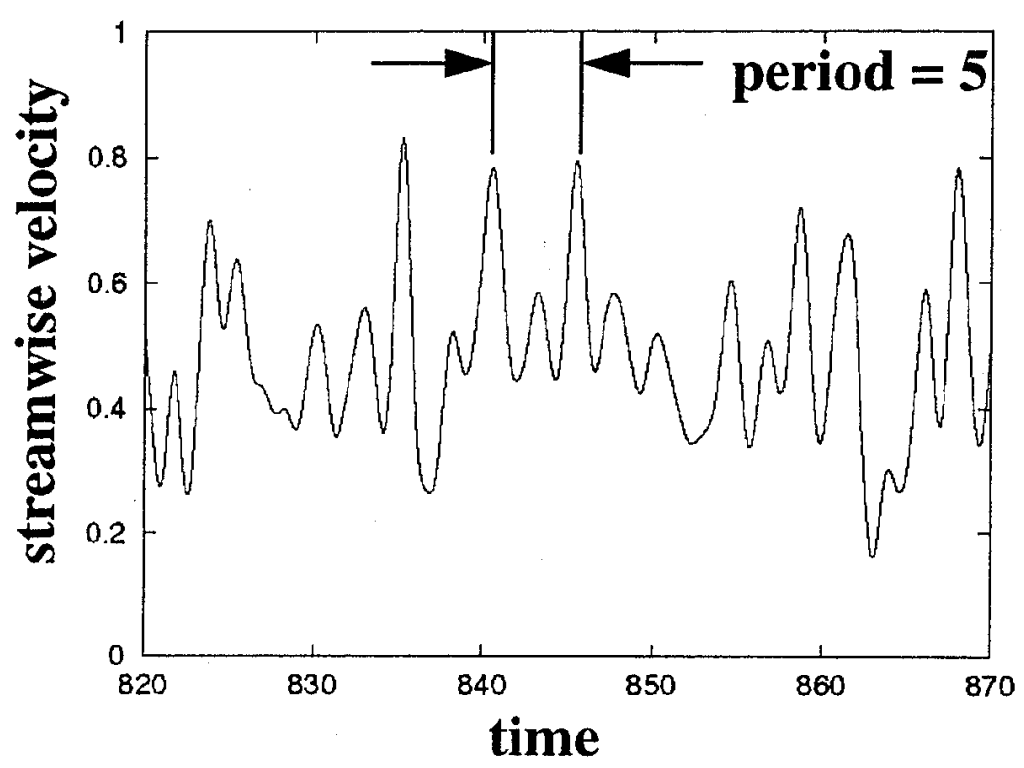

Goal: Use power spectrum to compare runs

- different meshes

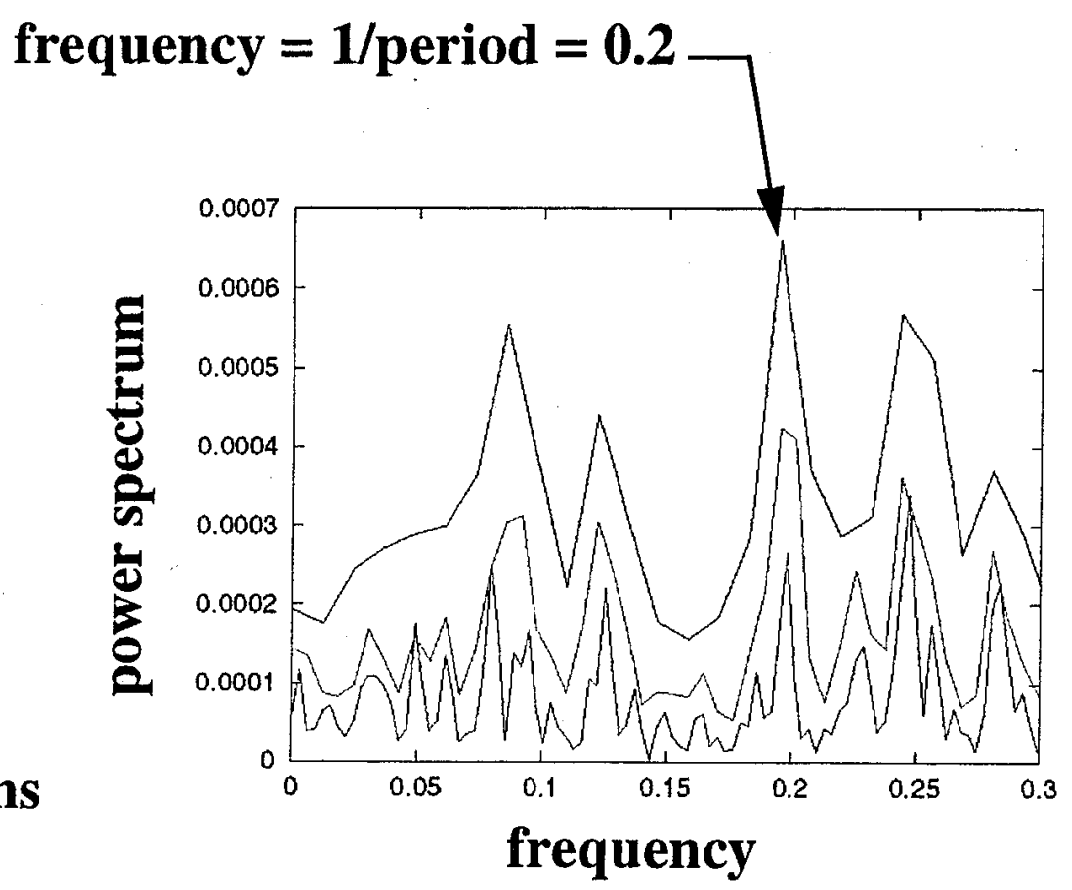

- different time steps

Issue: Peak identification 


\section{Flow visualization requires choosing the right parameters and movie making.}

\section{Pressure}

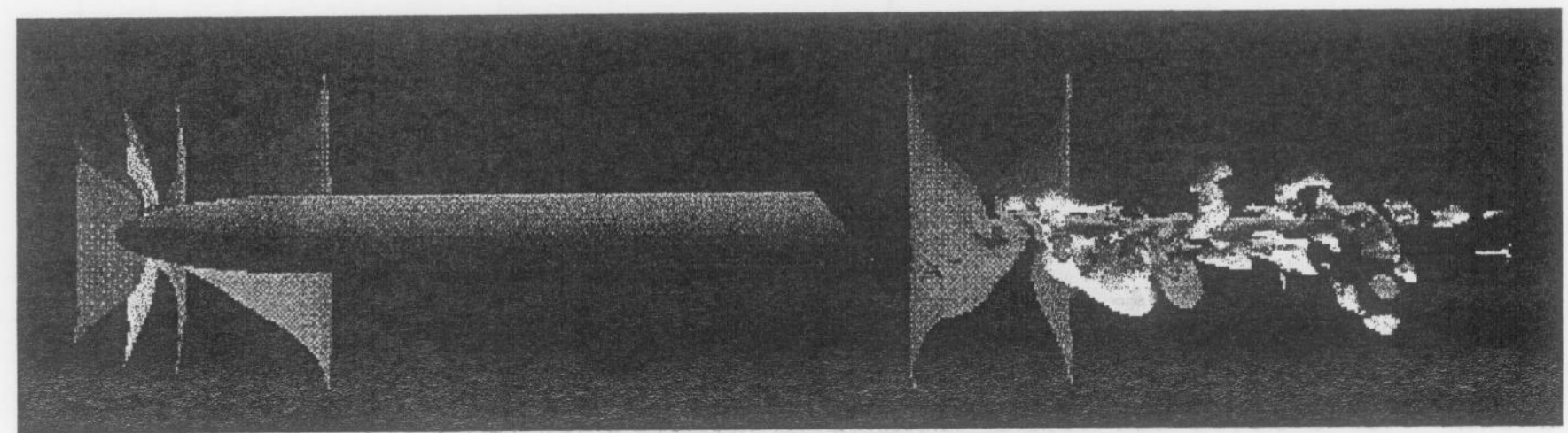

Large-Eddy Simulation of vortex shedding in the wake of a bluff body.

\section{Enstrophy}

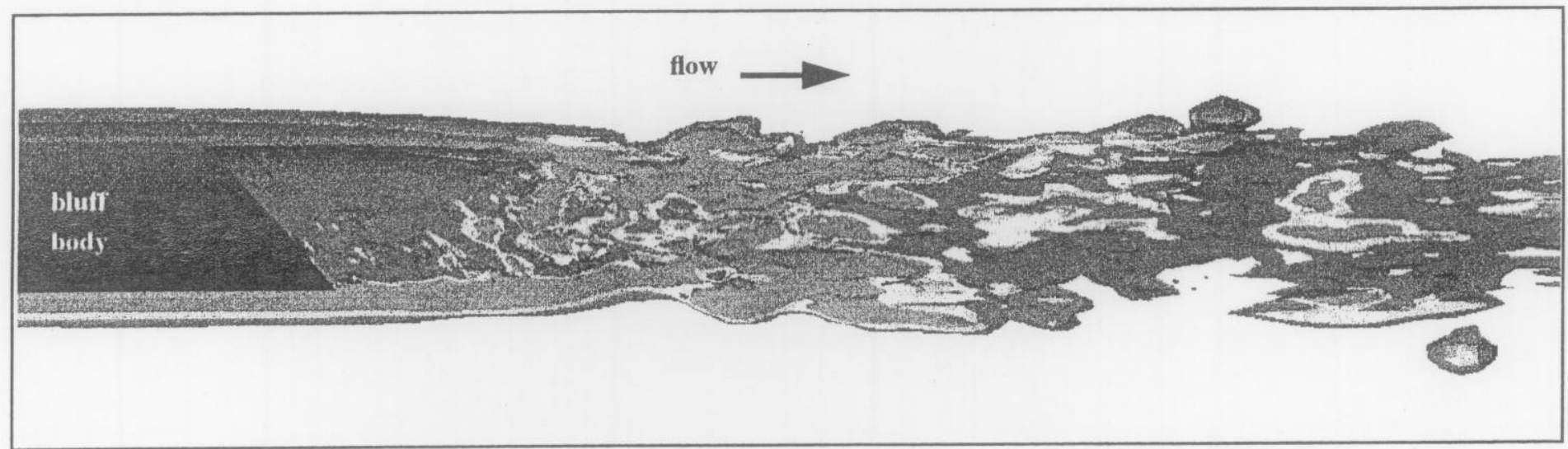


The first year deliverable is to integrate and develop the flow model and complete the demonstration problem.

Milestone

FY99 incompressible flow demonstration

$\mathbf{R} \& \mathbf{D}$

Solver integration/parallelization

Turbulence modeling

Boundary conditions

Data analysis

Computational domain is chosen to minimize grid size

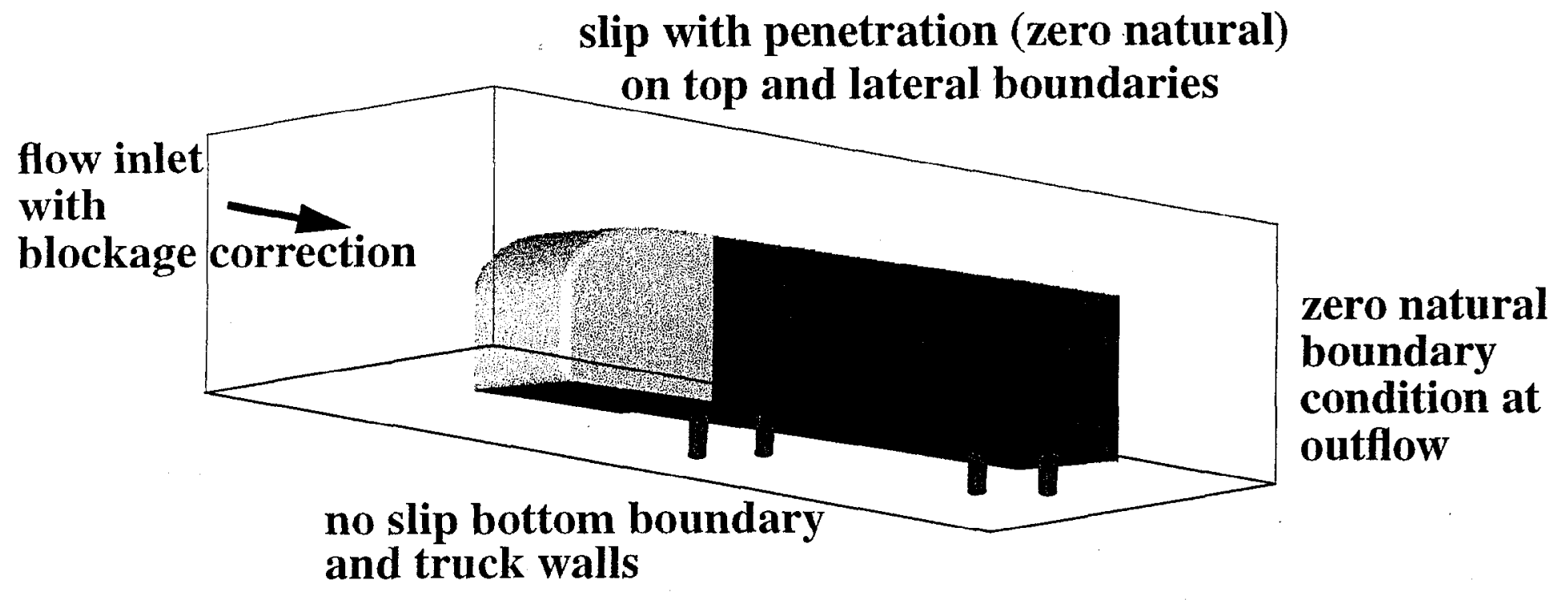


LES is a challenge but we have the experience and resources to succeed.

\section{LES/FEM has advantages}

Less empiricism

Built-in outflow conditions

Data analysis

Time-averaging, visualization, time histories, and power spectrum

\section{Approach}

Take advantage of existing methods and codes

Keep it simple - Smagorinsky SGS model and reduced computational domain 



\section{7x10 Test of the GTS Model}

CFD Validation for Heavy Vehicle Drag NASA Ames Research Center

October 22, 1998 


\section{7 x 10 Capabilities}

Tunnel Speed $\leq 235 \mathrm{mph}(\mathrm{q} \sim 140 \mathrm{psf}, \mathrm{M}=0.30)$

Test-section turbulence intensities:

$$
0.14 \%, 0.30 \%, 0.34 \%(\mathrm{u}, \mathrm{v}, \mathrm{w}) \text { at } \mathrm{M}=0.2
$$

Facility balance capacities:

Normal Force: $1800 \mathrm{lbs}$ rt \& lft, 800 lbs rear

Side Force: $\quad \pm 2000$ front, \pm 500 rear

Axial Force: $\quad \pm 500 \mathrm{lbs}$ ( $\pm 1 \mathrm{lb}$ accuracy)

PSI system (surface pressures):

$\pm 0.1 \%$ full scale accuracy 


\section{Top View}

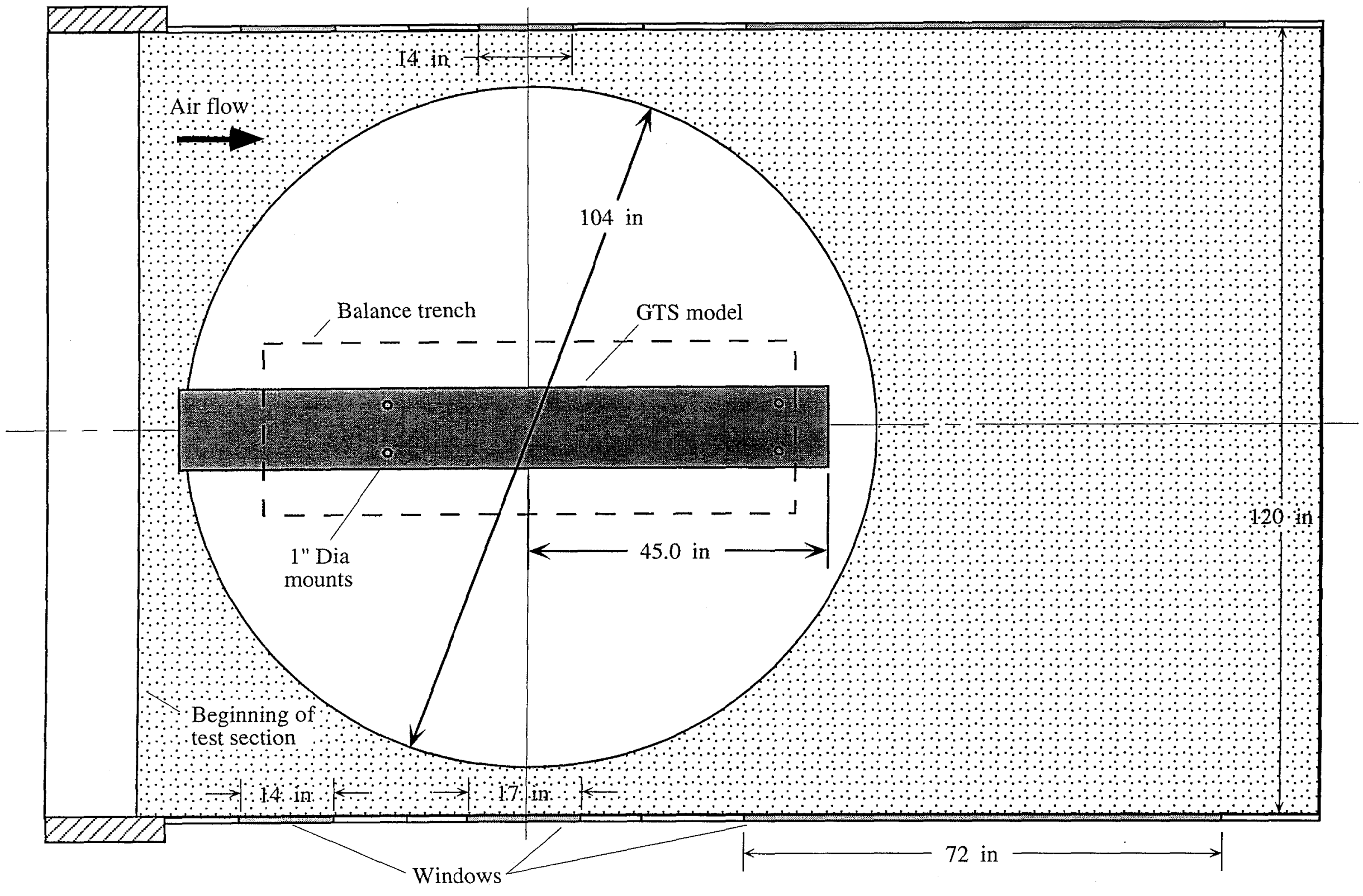

GTS Model: Ames 7x10 Installation

Scale: $1^{\prime \prime}=1.75^{\prime}$ 


\section{GTS Test Conditions}

Tunnel Speed $=200 \mathrm{mph}(\mathrm{q} \sim 105$ psf, $\mathrm{M}=0.27)$

Estimated drag (wind axis): $\quad \psi=0^{\circ} \quad \psi=14^{\circ}$

$$
\begin{aligned}
& \mathrm{q}=105 \text { psf: } \quad \mathrm{D}=41 \mathrm{lbs} \quad 120 \mathrm{lbs} \\
& q=80 \text { psf: } \quad D=31 \mathrm{lbs} \quad 92 \mathrm{lbs}
\end{aligned}
$$

Yaw angle: $-14^{\circ}<\psi<+14^{\circ}$ for forces $\&$ mom, pressures

$$
\begin{aligned}
& 0^{\circ}, 5^{\circ}, \& 10^{\circ} \text { for PSP } \\
& 0^{\circ} \& 10^{\circ}\left(\text { or } 5^{\circ}\right. \text { ) for PIV }
\end{aligned}
$$

Model configuration: Baseline, no wheels

Mounted 3 inches from tunnel floor 


\section{Flow Measurements}

Particle Image Velocimetry

Accuracy: $\mathrm{u}= \pm 3.4 \%, \mathrm{v} \& \mathrm{w}= \pm 1.7 \%$

Time to acquire: $~ 10 \mathrm{~min} /$ condition (1000 samples)

Pressure-Sensitive Paint

Accuracy: $\mathrm{Cp} \pm 0.03$

Acquisition time: $30 \mathrm{~min} /$ condition

Skin friction by Taos Hot-Film System

Separation, Reattachment, Transition detection

Oil Film Interferometry - Quantitative skin friction

Wall pressures, surface pressures, force $\&$ moments 


\section{Test Schedule}

Test window : January 4 - 22, 1999 (3 weeks)

Activity

Installation / Check-out

Forces \& Pressures

Pressure-sensitive paint

Particle image velocimetry

Removal

Total $\underline{\text { shifts }}$

2

1

4

7

1

15 


\section{Issues}

- Center of rotation closer to turntable centerline

- Tunnel speed significantly higher than previous test

- Second yaw angle: 5 or $10 \mathrm{deg}$ ??

- Wall pressures: yes yno ??

- PIV measurement stations ? >> parallel \& perp. to freestream

- PSP on side and back only ? >> OK

- Skin friction measurement location ? >> TBD

- Oil film interferometry for quantitative skin friction?

$>>$ on tunnel floor behind model 


.




\section{Heavy Vehicle Test in 7x10 at NASA Ames Research Center}

\section{PIV Overview}

J.T. Heineck, PIV Task Manager

Experimental Physics Branch

NASA Ames Research Center 


\section{NASA Ames PIV Team - Capabilities}

- Both 2D and 3D vectors for planar measurements

- $2 \%$ accuracy for instantaneous in-plane measurements, $4 \%$ for cross-plane. Time averaging improves statistical accuracy for steady flows.

- Images acquired and data processed on Windows NT system.

- $\quad$ CFD Grid Matching

- Team Experience in Wind Tunnel Testing

- Uses: Vortex Structure and Position, CFD Validation, Shear Layers, Jets, Flames

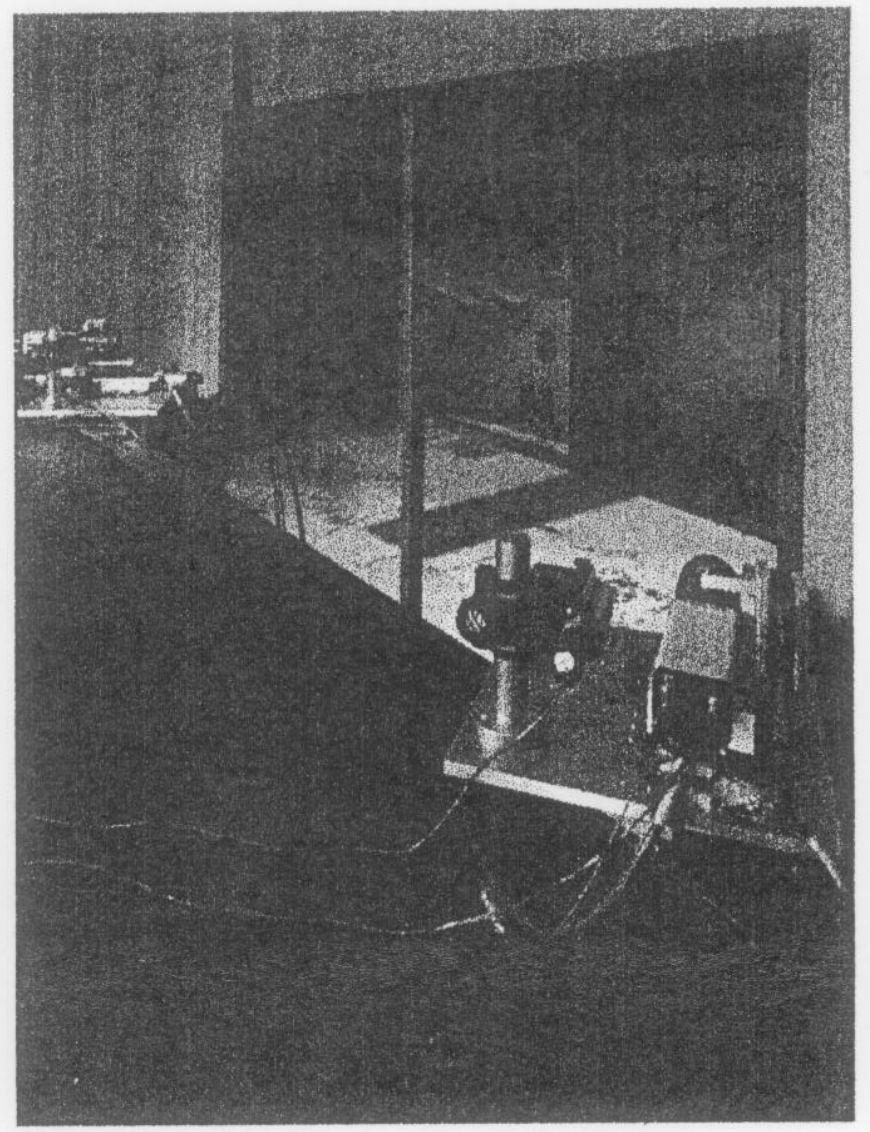




\section{The PIV Method}

- The seeded flow is illuminated with dual head pulsed Nd:YAG laser. Laser is optically shaped to form a sheet $1 \mathrm{~mm}$ thick and spans the region of interest.

- Special high-resolution, dual-exposure digital camera(s) is (are) focused using high resolution lenses on the plane of the laser sheet.

- Timing of pulses are spaced in microseconds, the cameras are synchronized to the laser.

- Images taken are of individual particles in the area of interest.

- The image pair undergoes cross correlation using Fourier methods.

- The distance and direction the particle image shifts at grid points are determined

- Vectors are calculated based on these shifts. The vector field is the resulting data. 


\section{PIV Issues for Tunnel Testing}

- Identify the region of interest and flow structure

- Determine the data required e.g. 2D vs. 3D, axial and/or orthogonal to free stream, level of statistical accuracy for Reynolds averaged velocities.

- Laser is powerful, may damage the surface or paint of some models

- Consistency of seeding will effect efficiency of data collection and quality of data

- Calibration and focus procedures take approximately 1-2 hours for a laser sheet location change

- 2 days of set up, 2 people needed to operate system.

- Data acquisition takes approximately 10 minutes per condition after tunnel stabilizes. 


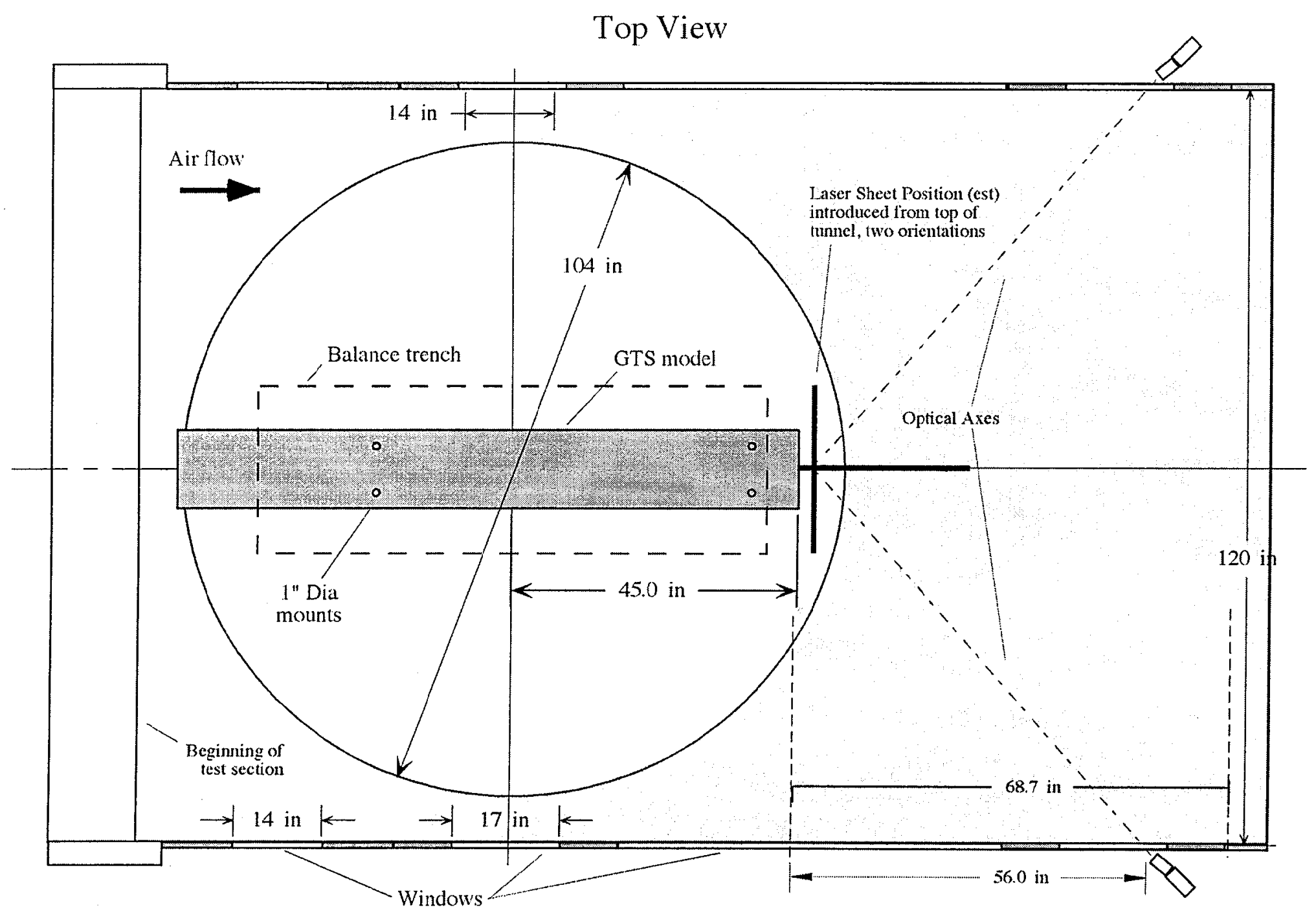

GTS Model: Ames 7x10 Installation

Scale: $1^{\prime \prime}=1.75^{\prime}$ 


\section{Sample Vector Image}

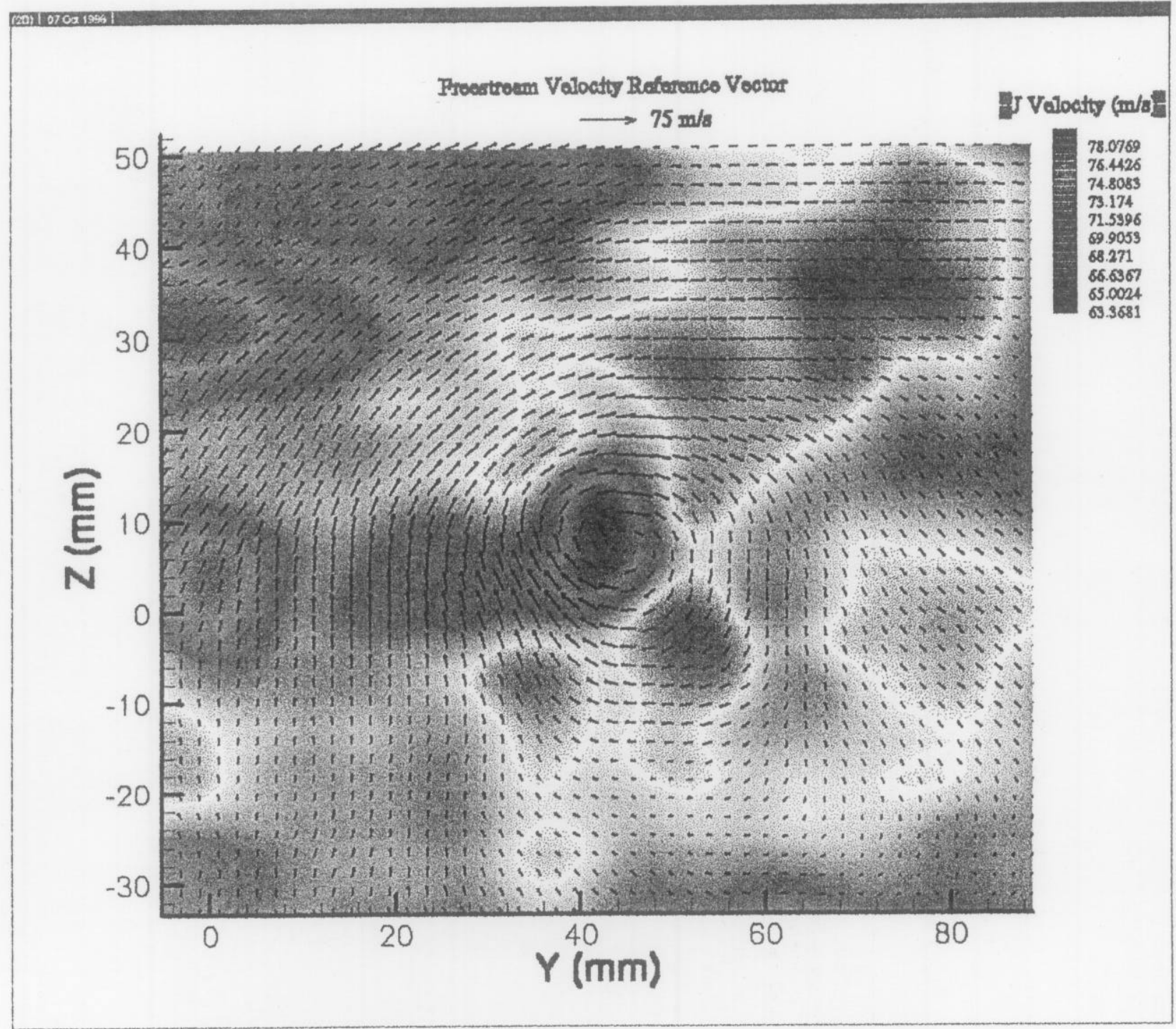

